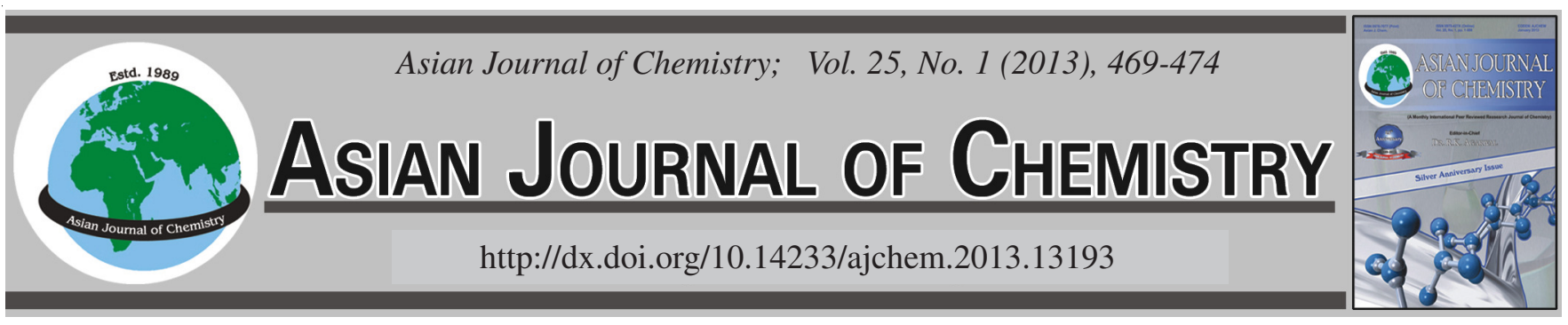

\title{
Effect of Oxalic Acid and Humic Acid on the Species Distribution and Activity of Fluoride in Soil
}

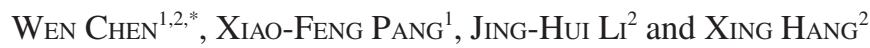

\begin{abstract}
${ }^{1}$ Institute of Life Science and Technology, University of Electronic Science and Technology of China, Chengdu 610054, P.R. China ${ }^{2}$ College of Material Chemistry and Chemical Engineering, Mineral Resources Chemistry Key Laboratory of Sichuan Higher Education Institutions, Chengdu University of Technology, Chengdu 610059, P.R. China
\end{abstract}

*Corresponding author: Fax: +86 28 84079074; Tel: +86 28 84078239; E-mail: chenwen2010@foxmail.com

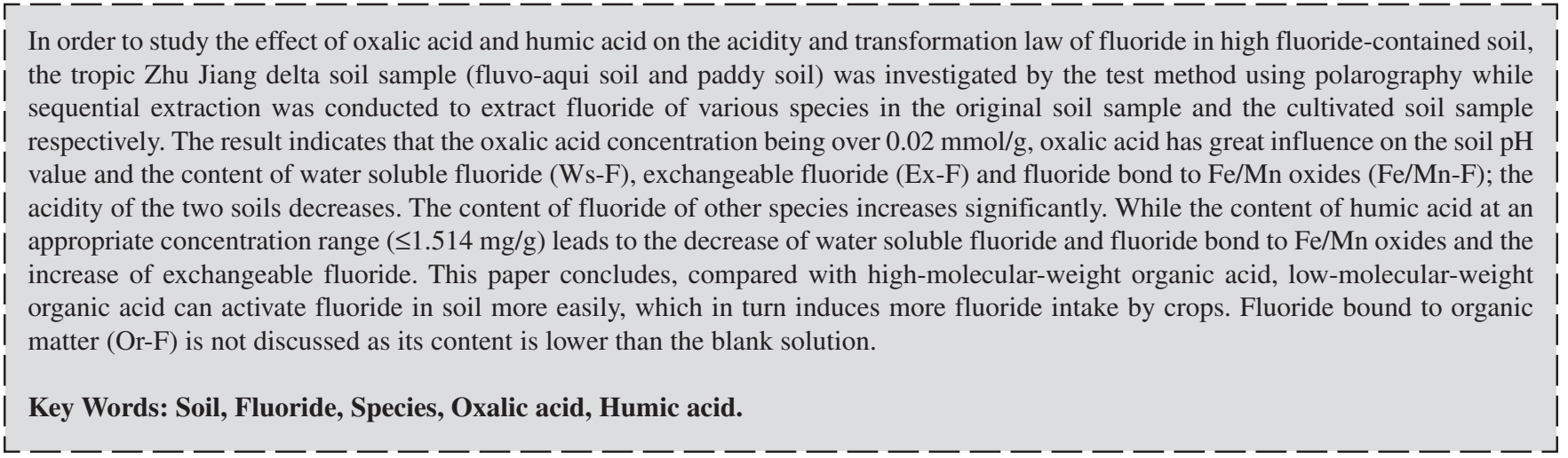

\section{INTRODUCTION}

Fluoride is closely related to people's health ${ }^{1}$ and the crop (foodstuff and vegetable) is an important source of fluoride for taking by human body ${ }^{2}$. The content of fluoride in crop is closely related to the species and activity of fluoride in soil ${ }^{3}$, which is affected by the soil environment ${ }^{4}$. Thus close attention, should be paid to the effects of organic acids.

There are two kinds of organic acids in soil, low molecular weight (LMW), such as oxalic acid and high molecular weight (HMW), such as humic acid.

Low molecular weight organic acids occur widely in soils and primarily originate from root exudation, plant residue decomposition and microbial metabolism ${ }^{5,6}$. The concentration of low molecular weight in soil solution could be up to $1 \times 10^{-4}$ $10^{-3} \mathrm{mmol} / \mathrm{L}^{7}$.

In addition, a weak high-molecular-weight organic acid, humic acid, is produced in the decomposition process of organic fertilizer in soil and in combination with inorganic colloid, forms a complex of organic-inorganic colloid ${ }^{8}$.

These organic acids would affect the species of fluoride in soil through competing with fluoride for soil sorption sites, or changing the properties of the soil surface and in turn affect the activity and bioavailability of fluoride in soil ${ }^{9,10}$. Therefore, the study on the species and availability of fluoride in soil may have both practical and theoretical significance.

Most of the existed researches about organic acid and fluoride in soil, to date, are ones on the effect of low-molecularweight organic acid on fluoride adsorption of soil ${ }^{11,12}$. These authors ${ }^{11,12}$ have studied the effect of citric acid and malic acid on the fluoride adsorption of soil. While Xu et al. ${ }^{13,14}$ have studied the effect of oxalic acid, malonic acid, citric acid on the fluoride adsorption of several variable charges soils. However, scanty of work related to the effect of high-molecular-weight organic acid on the fluoride adsorption of soil has been reported. And only a few researches about the effect of the organic acid on the species of fluoride and its activity in soil have been reported.

There are only a few researchers' reports about the effect of the organic acid on the species of fluoride and its activity in soil. In the researches, done by Liu et al. ${ }^{15}$, about the effect of citric acid and oxalic acid on the adsorption effect and distribution of fluoride species in the tea garden soil, the acids are found to have inhibiting effect to the fluoride adsorption of soil at low concentration of fluoride and vice-versa. Exogenous fluorine converts to various active species in soil, mainly to residual species and water soluble species. 


\begin{tabular}{lccccccccccc}
\hline \multicolumn{10}{c}{ TABLE-1 } \\
\hline \multirow{2}{*}{ Number } & $\begin{array}{c}\text { Depth } \\
(\mathrm{cm})\end{array}$ & $\begin{array}{c}\text { Clay } \\
(\%)\end{array}$ & $\begin{array}{c}\text { Colloidal } \\
\text { particle }(\%)\end{array}$ & $\begin{array}{c}\text { O.M. } \\
(\%)\end{array}$ & $\begin{array}{c}\text { CEC } \\
(\mathrm{mmol} / \mathrm{g})\end{array}$ & $\begin{array}{c}\mathrm{pH} \\
\left(\mathrm{H}_{2} \mathrm{O}\right)\end{array}$ & $\begin{array}{c}\text { Eh } \\
(\mathrm{mv})\end{array}$ & $\begin{array}{c}\text { Total Fe } \\
(\%)\end{array}$ & $\begin{array}{c}\text { Total Al } \\
(\%)\end{array}$ & $\begin{array}{c}\text { Total Mn } \\
(\mu \mathrm{g} / \mathrm{g})\end{array}$ & $\begin{array}{c}\text { Total F } \\
(\mu \mathrm{g} / \mathrm{g})\end{array}$ \\
\hline Fluvo-aquic soil & $0-30$ & 23.00 & 12.05 & 2.14 & 0.12 & 6.01 & 221.63 & 6.085 & 14.89 & 511.6 & 603.8 \\
Paddy soil & $0-30$ & 30.25 & 15.75 & 1.08 & 0.11 & 5.79 & 255.0 & 6.442 & 21.80 & 889.8 & 851.8 \\
\hline
\end{tabular}

The effect of citric acid and succinic acid on the adsorption effect and distribution of fluoride in the tea garden soil have led to the similar conclusion and have proved that the higher the concentration of exogenous fluoride, the greater the acid can activate the fluoride adsorption effect of soil ${ }^{10}$.

However, these researches have only studied the effect of low-molecular-weight organic acid on the fluoride adsorption. Studies have been done neither on the effect of the amount of organic acids added on fluoride species nor on that of highmolecular-weight organic acid. Moreover, the studies of the effect on the fluoride species is concerned to the effect of organic acids on the distribution of the exogenous fluorine, but not on the change of the fluoride species and activity of the fluoride contained by the original soil. However, for fluoride contained soil, especially for high fluoride-contained soil, this is the point that should be attached great significance to. Because it will affect the fluoride intake of crops and in turn that of human and stocks.

Taking oxalic acid and humic acid as examples, this paper conducts a comparative study on the effects of different organic acids (low molecular weight and high molecular weight) on the transformation of species and activity of fluoride in soil and on the difference of the effects, to provide a more comprehensive understanding of the migration and transformation laws of fluoride in the soil and a theoretic reference for artificial regulating and controlling the soil condition and reducing the fluoride content of crops.

\section{EXPERIMENTAL}

Standard fluoride stock solution $(500 \mu \mathrm{g} / \mathrm{mL}): 0.5525 \mathrm{~g}$ sodium fluoride (AR, Chengdu Kelong Chemical plant), dried at $120^{\circ} \mathrm{C}$ for $2 \mathrm{~h}$, were weighed into a beaker and dissolved in distilled water. The solution was then transferred into a 500 $\mathrm{mL}$ volumetric flask, brought to volume by distilled water and stored in a plastic bottle. The working solution was stepwise diluted from such stock solution.

The standard salicyl fluoronel (SAF) stock solution (1.0 $\times 10^{-3} \mathrm{~mol} / \mathrm{L}$ ): $0.0336 \mathrm{~g} \mathrm{SAF}$ (AR, Tianjing Chemical Regent Research Institute) was weighted into a breaker followed by addition of $5.0 \mathrm{~mL}$ absolute ethyl alcohol and $0.4 \mathrm{~mL}$ hydrochloric acid solution $(6.0 \mathrm{~mol} / \mathrm{L})$. After SAF being dissolved, the solution was diluted to $100 \mathrm{~mL}$ with absolute ethyl alcohol and stored in dark place.

The $\mathrm{Zr}(\mathrm{IV})$ stock solution $(200 \mu \mathrm{g} / \mathrm{mL}): 0.0707 \mathrm{~g}$ $\mathrm{ZrOCl}_{2} .8 \mathrm{H}_{2} \mathrm{O}$ (AR, Chengdu Ke Long Chemical regent plant) was prepared to be heated in $10 \mathrm{~mL}$ hydrochloric acid solution $\left(2 \mathrm{~mol} \mathrm{~L}^{-1}\right)$ and kept boiling for several minutes. When cooled, the solution was diluted with $2 \mathrm{~mol} \mathrm{~L}^{-1} \mathrm{HCl}$ to $100 \mathrm{~mL} \mathrm{Zr}(\mathrm{VI})$ solution of $200 \mu \mathrm{g} / \mathrm{mL}$. The working solution of $\mathrm{Zr}(\mathrm{VI})$ was obtained by diluting the stock solution with $2 \mathrm{~mol} \mathrm{~L}^{-1} \mathrm{HCl}$ to $10 \mu \mathrm{g} / \mathrm{mL}$. $1 \mathrm{~mL}$ polyethylene glycol $(0.01 \mathrm{wt} \%)$ was used to sensitize the peak currents of salicyl fluoronel. It was prepared by $0.01 \mathrm{~g}$ polyethylene glycol (m.w. 20000) (AR, Chengdu Ke Long Chemical plant) diluted to $100 \mathrm{~mL}$. All other reagents were of analytical reagent grade and distilled water was used throughout.

Linear sweep voltammetric experiments were carried out by using a model JP-303 polarographic analyzer (Chengdu Apparatus Factory, China) with a dropping mercury working electrode (DME), a SCE reference electrode and a platinumwire counter electrode. All the $\mathrm{pH}$ values were measured with a pHS-2C acidity meter (Shanghai Dazhong analytical Instrument Plant, China).

Preparation of soil sample: Two soil samples, fluvo-aquic soil (Longshan), sampling from Wang gang Town, Longshan County, Shunde city in Guangdong Province and paddy soil (Dawang), sampling from Da wang Farm, Sihui City, Zhao Qing in Guangdong Province, were selected for this experiment. They were collected from the top layer in 0-30 cm depth. They are air-dried and ground to pass a 2-mm sieve respectively to sieve the grit and plant residue out. The selected soil properties are given in Table- 1 .

The samples were cultivated by organic acid (oxalic acid and humic acid) of increasing volume, according to Table-2. By adding proper amount of distilled water, the total volume was kept at $25 \mathrm{~mL}$, making the samples swamped and halfswamped at $8-10{ }^{\circ} \mathrm{C}$ for 3 month and then air-dried and grounded to pass $0.25-\mathrm{mm}$ and $0.08-\mathrm{mm}$ sieve respectively.

\begin{tabular}{ccccccc}
\multicolumn{8}{c}{ TABLE-2 } \\
AMOUNT OF ORGANIC ACIDS IN SOIL \\
\hline Number & 1 & 2 & 3 & 4 & 5 & 6 \\
\hline $\begin{array}{c}\text { Oxalic acid } \\
\text { (mmol/g) }\end{array}$ & 0.004 & 0.008 & 0.012 & 0.016 & 0.02 & 0.024 \\
\hline $\begin{array}{c}\text { Humic acid } \\
\text { (mg/g) }\end{array}$ & 0.114 & 0.19 & 0.379 & 0.757 & 1.136 & 1.514 \\
\hline
\end{tabular}

Determination of the total content of fluoride: Take some soil samples (passed through 0.08-mm sieve). After the soil samples were melting with $\mathrm{NaOH}$ at $600{ }^{\circ} \mathrm{C}^{16}$, the total content of fluoride could be determined by using proposed method.

Sequential extraction of varies species of fluoride: $2.5 \mathrm{~g}$ soil samples (passed through $0.25-\mathrm{mm}$ sieve) was weighted into a $50 \mathrm{~mL}$ plastic centrifuge tube, followed by addition of $25 \mathrm{~mL}$ extract solution. Various species of fluoride were extracted sequentially, in accordance with the procedure of Table- $3{ }^{17}$. After every species have been extracted, the volume of extract solution was measured with a $50 \mathrm{~mL}$ graduated cylinder and the result should exclude the content of $\mathrm{F}$, brought by residual solution.

Determination of soil pH: After being air-dried and ground to pass a $0.25-\mathrm{mm}$ sieve. $1 \mathrm{~g}$ soil was soaked in 2.5 $\mathrm{mL}$ distilled water (soil-to-distilled water ratio: 1:2.5). The $\mathrm{pH}$ value of the solution was then determined by the PXS-5 
TABLE-3

SEQUENTIAL EXTRACTION PROCEDURE FOR FRACTIONATE SPECIES IN SOIL

\begin{tabular}{lll}
\hline Fluoride species & Extract & Condition \\
\hline Ws-F & Distilled water & Shake for $0.5 \mathrm{~h}$ at $60^{\circ} \mathrm{C}$ \\
Ex-F & $1.0 \mathrm{~mol} / \mathrm{LMgCl}_{2}(\mathrm{pH}=7)$ & Shake for $1 \mathrm{~h}$ at $25^{\circ} \mathrm{C}$ \\
$\mathrm{Fe} / \mathrm{Mn}-\mathrm{F}$ & $0.04 \mathrm{~mol} / \mathrm{L} \mathrm{NH} \mathrm{HH}_{2} \mathrm{OHCl}$ & Shake for $1 \mathrm{~h}$ at $60^{\circ} \mathrm{C}$ \\
Or-F & Step 1: $3 \mathrm{~mL}, 0.02 \mathrm{~mol} / \mathrm{L}, \mathrm{HNO}_{3}+10 \mathrm{~mL} 30 \% \mathrm{H}_{2} \mathrm{O}_{2}$ & Step 1and 2 step: shake for $0.5 \mathrm{~h} \mathrm{at} 25^{\circ} \mathrm{C}$ \\
& Step 2: Add into $12 \mathrm{~mL}, 3.2 \mathrm{~mol} / \mathrm{L} \mathrm{NH} \mathrm{N}_{4} \mathrm{Ac}$ & \\
Res-F & The total fluoride content of soil minus the total fluoride content of other species & \\
\hline
\end{tabular}

pH meter (Shanghai Da Zhong Analytical Instrument Plant, China).

Determination of fluoride: To a dry $25 \mathrm{~mL}$ colourimetric tube, solutions were added in the following order: $3 \mathrm{~mL}$ standard solution of $\mathrm{Zr}(\mathrm{IV})(10 \mathrm{mg} / \mathrm{L}), 3 \mathrm{~mL} \mathrm{HCl}$ solution $(2 \mathrm{~mol} / \mathrm{L}), 3.5 \mathrm{~mL}$ salicyl fluoronel solution $\left(1.0 \times 10^{-3} \mathrm{~mol} / \mathrm{L}\right)$, $1 \mathrm{~mL}$ polyethylene glycol (PG) solution (Mw 20000, 0.01 wt \%) and an appropriate amount of standard fluoride or sample solution. The mixture were diluted to $25 \mathrm{~mL}$ with distilled water and shaken up adequately. The second order derivative linear sweep voltammetric peak currents (ip") were recorded in the potential range from $-0.30 \mathrm{~V}$ to $-1.30 \mathrm{~V}(v s$. $\mathrm{SCE}$ ) at room temperature, scan rate and standing time is 500 $\mathrm{mv} / \mathrm{s}$ and $8 \mathrm{~s}$, respectively ${ }^{18}$. The result of fluoride content of the object sample was the average of three measurements. In addition, extract of organic species should be heated to decompose $\mathrm{H}_{2} \mathrm{O}_{2}$ before measurement.

\section{RESULTS AND DISCUSSION}

Effect of organic acid on soil $\mathrm{pH}$ values at different concentration: Fig. 1 showed that the effects of oxalic acid and humic acid (from Shanghai Chemical regent plant) on the two soil $\mathrm{pH}$ values which are closely related to the type of the soil and the $\mathrm{pH}$ value of the soil. Table- 1 showed that the original $\mathrm{pH}$ value of the fluvo-aquic soil is higher than that of paddy soil. Thus, the same tendency, as a whole, can be observed, with the increasing of organic acid concentration.

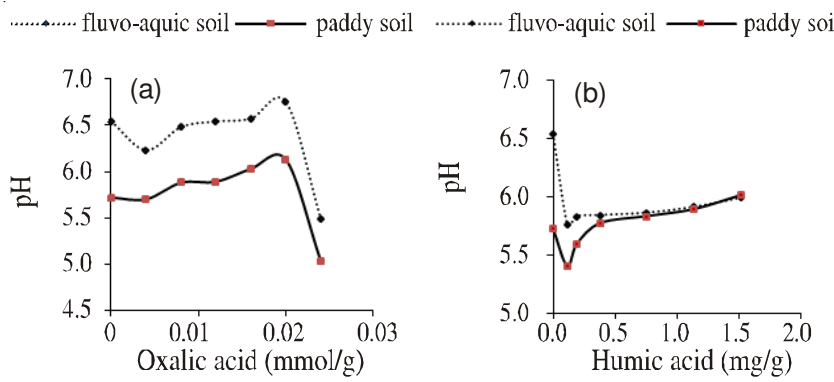

Fig. 1. Effect of oxalic acid and humic acid on soil pH; (a) Effect of oxalic acid on soil $\mathrm{pH}$; (b) Effect of humic acid on soil $\mathrm{pH}$

However, differences lie in that, in the case of the oxalic acid system, the $\mathrm{pH}$ value of the soil increases slightly and steadily with the increasing of oxalic acid concentration and no sharp decrease was observed before the oxalic acid concentration reaches $0.02 \mathrm{mmol} / \mathrm{g}$. Whereas, in the case of humic acid, the acid initially induces a decrease in $\mathrm{pH}$ values of the two soils, then $\mathrm{pH}$ values increase with the increasing concentration though the acidity of fluvo-aquic soil is always lower than that of the original soil sample; and that of paddy soil higher than that of the original soil sample.
This indicates that the effect of oxalic acid on the soil $\mathrm{pH}$ values at different concentration is determined by the concentration of oxalic acid. Whereas, in case of the humic acid by the property of the soils themselves.

The possible mechanisms could be that, at an organic acid system of low concentration, $\mathrm{H}^{+}$in the two organic acids plays a dominant role and leads to a low soil $\mathrm{pH}$ value. Oxalic acid is a common dicarboxyl organic acid in soil ${ }^{19}$, whose molecular structure is HOOC-COOH; while, with various kinds of functional group, such as hydroxyl, alcohol hydroxyl, pheudic hydroxyl methoxyl and the humic acid has a more complex molecular structure. And the weak acidity of the two organic acids is mainly provided by $-\mathrm{COOH}$ and $-\mathrm{OH}$. As the concentration of the organic acids increases, the $-\mathrm{COOH},-\mathrm{OH}$, or $-\mathrm{CH}_{2} \mathrm{OH}$ in the two organic acids can exchange with the fluoride ions in soil and $\mathrm{OH}^{-}$can be released ${ }^{20}$.

$$
\begin{aligned}
-\mathrm{COOH}+\mathrm{F}^{-} & \rightleftharpoons-\mathrm{COF}+\mathrm{OH}^{-} \\
-\mathrm{CH}_{2} \mathrm{OH}+\mathrm{F}^{-} & \rightleftharpoons-\mathrm{CH}_{2} \mathrm{~F}+\mathrm{OH}^{-} \\
-\mathrm{OH}+\mathrm{F}^{-} & \rightleftharpoons \mathrm{F}+\mathrm{OH}^{-}
\end{aligned}
$$

Through mutually neutralizing of the released $\mathrm{OH}^{-}$and the dissociated $\mathrm{H}^{+}$, the soil $\mathrm{pH}$ values increase slightly. And as the acid concentration increases, the amount of $\mathrm{H}^{+}$again surpasses that of $\mathrm{OH}^{-}$, which in turn decreases the $\mathrm{pH}$ values. In this study, the concentration of oxalic acid is relatively high and a significant decrease of soil $\mathrm{pH}$ values is finally observed. Whereas that of humic acid is relatively low, thus no such decrease occurs.

Effect of organic acid on various species of fluoride at different concentration: The total content of fluoride and the content of various species of fluoride in the original soil sample and the cultivated soil sample determined by using proposed method and the results are presented in Table-4 (Fig. 2 and Fig. 3).

Effect of the amount of oxalic acid and humic acid added on the content of water soluble fluoride (Ws-F): The water soluble fluoride is mainly referred to as the fluoride in soil and solution taking forms of ion and complex, including $\mathrm{F}^{-}, \mathrm{HF}_{2}^{-}, \mathrm{H}_{2} \mathrm{~F}_{3}^{-}, \mathrm{H}_{3} \mathrm{~F}_{4}^{-}, \mathrm{AlF}_{6}{ }^{3-}, \mathrm{FeF}_{6}{ }^{3-}$, etc. ${ }^{21}$.

From Fig. 2 (a), when the concentration of oxalic acid is under $0.02 \mathrm{mmol} / \mathrm{g}$, the concentration of fluoride in solution almost remains as the same with the increase of oxalic acid concentration. However, when beyond that, an apparent increase of the fluoride concentration in solution is observed.

\begin{tabular}{lccccc}
\multicolumn{7}{c}{ TABLE-4 } \\
CONTENT OF VARIOUS SPECIES OF FLUORIDE \\
IN ORIGINAL SOIL SAMPLES $(\mu \mathrm{g} / \mathrm{g})$ \\
\hline Sample & Ws-F & Ex-F & Fe/Mn-F & Res-F & Total-F \\
\hline Fluvo-aquic soil & 7.077 & 13.352 & 1.895 & 660.596 & 682.92 \\
Paddy soil & 1.373 & 6.539 & 0.896 & 841.859 & 850.667 \\
\hline
\end{tabular}



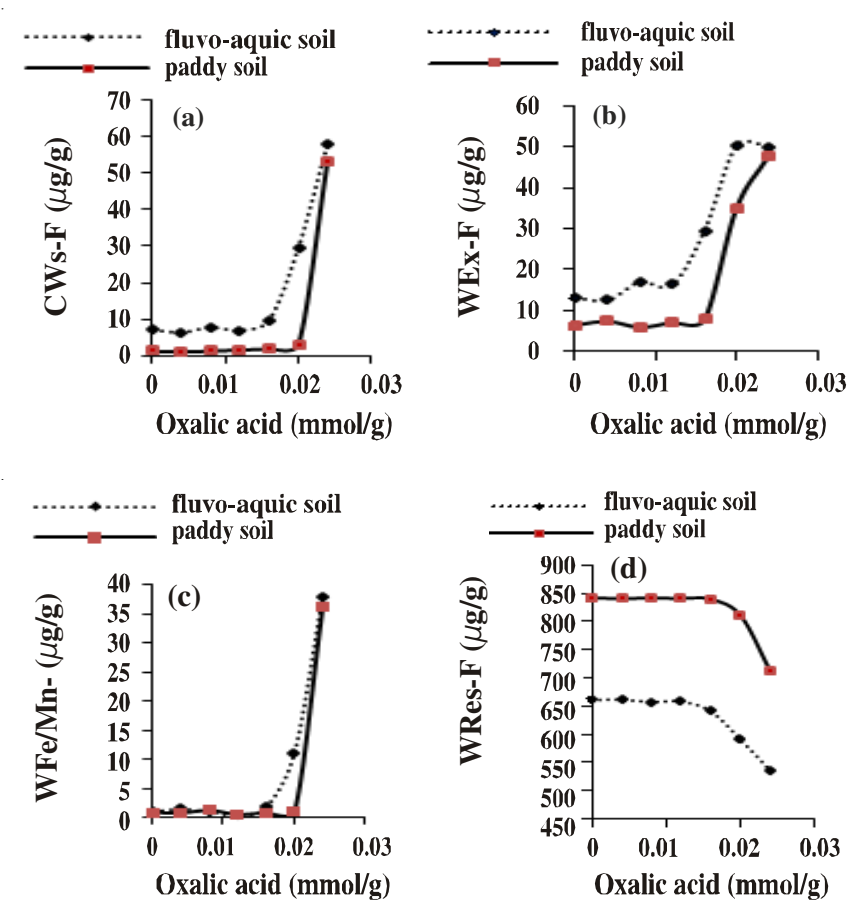

Fig. 2. Effect of oxalic acid on varies species of fluorine; (a) Effect on water soluble fluoride; (b) Effect on exchangeable fluoride; (c) Effect on Fe/Mn-F; (d) Effect on residual fluoride
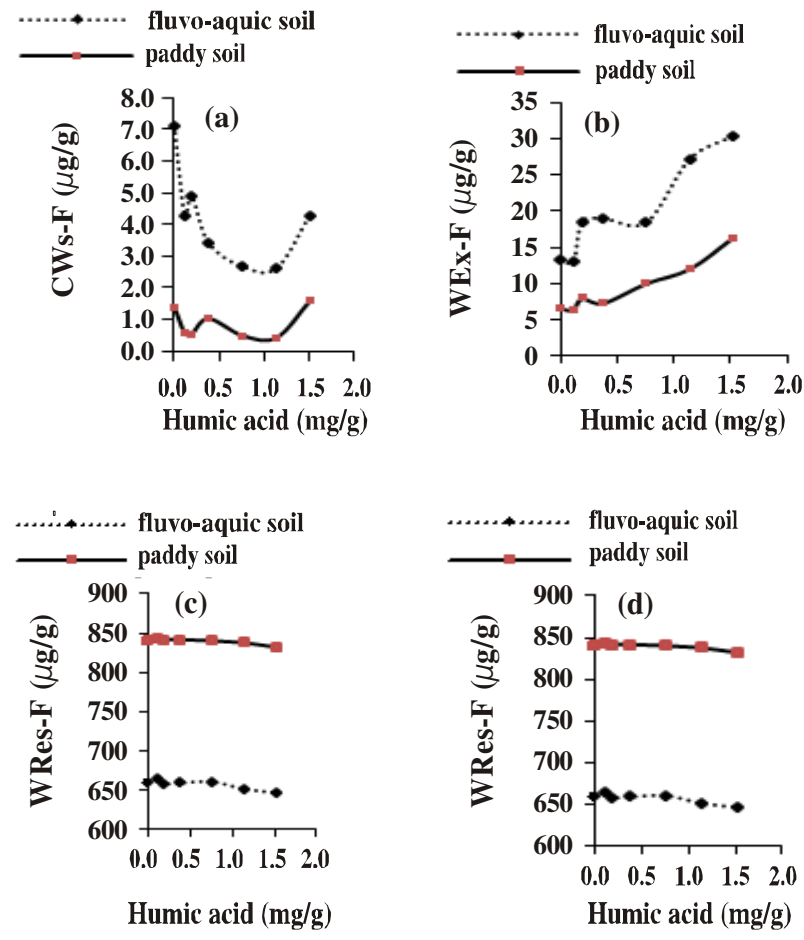

Fig. 3. Effect of humic acid on varies species of fluorine; (a) Effect on water soluble fluoride; (b) Effect on exchangeable fluoride; (c) Effect on $\mathrm{Fe} / \mathrm{Mn}-\mathrm{F}$; (d) Effect on residual fluoride

From Table-1 (properties of the test soil), the total amount of $\mathrm{Fe}$ and $\mathrm{Al}$ is much higher in these soils, a certain amount of $\mathrm{Fe}$ and $\mathrm{Al}$ in them would be dissociated with the increase of organic acid and they would then exist in form of Al-F and Fe-F complex. At the same time, H-F ions might also be formed. Therefore, the concentration of water soluble fluoride increases.
Fig. 3(a) shows, at a humic acid concentration ranging from 0 to $1 \mathrm{mg} / \mathrm{g}$, the concentration of water soluble fluoride decreases as the humic acid concentration increases. The possible mechanism could be responsible for this is, the formation of chelate fluoride and Or-F, caused by the complex effect between water soluble fluoride and humic acid.

At a humic acid concentration of $1.54 \mathrm{mg} / \mathrm{g}$, the water soluble fluoride of both fluvo-aquic soil and paddy soil increase, with the later one resuming the content of the original soil sample, but the former one not.

Two possible mechanisms: First, bearing anions, the increasing humic acid would compete with fluoride for soil sorption sites. Therefore, some fluoride, bound with Fe, Al, $\mathrm{Mn}$, would be dissociated, which in turn increase the water soluble fluoride, second, with the increase of acidity, a small amount of $\mathrm{Fe}$ and $\mathrm{Al}$ is dissociated and then water soluble fluoride is formed.

Overall, oxalic acid increases the water soluble fluoride in soil only when it's at a high concentration. Whereas, humic acid inhibits the increase of water soluble fluoride at a certain concentration range, which in turn decrease the bioavailability of fluoride. Therefore, adding proper amount $(\leq 1.514 \mathrm{mg} / \mathrm{g})$ of humic acid to soil with high fluoride concentration can reduce the harm of fluoride.

Effect of the amount of oxalic acid and humic acid added on the content of exchangeable fluoride (Ex-F): The exchangeable fluoride is referred to as the fluoride anions adsorbed on the exchangeable positive charge of cosmid, organic matter particle and hydrous oxide by electrostatic force.

From Fig. 2(b), with the adding of oxalic acid, the content of exchangeable fluoride in fluvo-aquic soil is, in general, on the rise. Whereas, that in paddy soil only increases when the oxalic acid is at high concentration $(\geq 0.016 \mathrm{mg} / \mathrm{g})$.

The possible mechanism might be that the increasing oxalic acid increases the content of $-\mathrm{OH}$, used to exchange with fluoride anions, which induces the increase of exchangeable fluoride in soil, though such exchanging may differ with different physicochemical properties of soils.

Fig. 3(b) indicates, with the addition of humic acid, the content of exchangeable fluoride is on the rise, in general, which should be related to the acidity and strong adsorption effect of humic acid.

From Fig. 1, the increasing humic acid concentration decreases soil $\mathrm{pH}$ values, particularly for fluvo-aquic soil. According to eqns. (1) to (3), the increase of soil acidity promotes the reversible reaction of those equations and reduces the mutual exchange capacity of functional groups and fluoride, seeing an increase of the soil's capacity of adsorbing fluoride and the content of exchangeable fluoride in soil.

Overall, both of the two organic acids can increase the content of exchangeable fluoride in soil, particularly for the fluvo-aquic soil. Because of the exchangeable fluoride and water soluble fluoride, a general name is given-bioavailable fluoride. Both of the two organic acids have increased the bioactivity of fluoride in soil.

Effect of the amount of oxalic acid and humic acid added on the content of fluoride bound to $\mathrm{Fe} / \mathrm{Mn}$ oxides (Fe/Mn-F): Fluoride which can have adsorption and coprecipitation effect with the oxide, hydroxide and hydrous 
oxide of $\mathrm{Fe}, \mathrm{Mn}$ and $\mathrm{Al}$ is known as $\mathrm{Fe} / \mathrm{Mn}-\mathrm{F}$, the un-bioaviliable form of fluoride in soil.

From Fig. 2(c), when the concentration of oxalic acid is low, the content of $\mathrm{Fe} / \mathrm{Mn}-\mathrm{F}$ remains almost the same as the concentration of oxalic acid increases; when it is high, the increase of the oxalic concentration increases the content of $\mathrm{Fe} / \mathrm{Mn}-\mathrm{F}$.

The possible mechanism might be, the oxalic acid is a weak acid, with reduction properties and can replace and complex with anions. At a low concentration, the mentioned reactions between oxalic acid and the oxide and hydrous oxide of $\mathrm{Fe}$ and $\mathrm{Mn}$ are moderate. So, in soil, dealed with oxalic acid at different concentration, the content of Fe/Mn-F decreases slightly, which indicates, at such concentration, the oxalic acid have little effects on Fe/Mn-F.

However, when the concentration of oxalic acid reaches a certain extent, its capacity of acid solution, complexation and reduction increases and the high-charge ion $\mathrm{Fe}^{3+}, \mathrm{Mn}^{4+}$, $\mathrm{Mn}^{6+}$ are dissolved, some of which then are reduced to $\mathrm{Fe}^{2+}$, $\mathrm{Mn}^{2+}$, forming their oxid and hydrous oxid.

Shao et al. ${ }^{22}$ have found that the coordinated carboxyl on the surface of oxide would exchange ligand with $\mathrm{F}^{-}$, which would be specifically adsorbed and a large amount of $\mathrm{OH}^{-}$is released, in accordance with equations as follow:

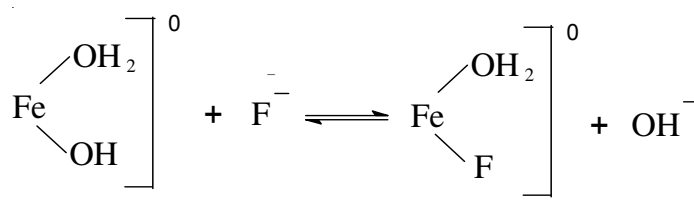

The increasing acidity promotes the neutralization of $\mathrm{H}^{+}$ and $\mathrm{OH}^{-}$, triggering the reaction. Thus, the content of $\mathrm{Fe} / \mathrm{Mn}-\mathrm{F}$ in soil increases with the increase of the oxide of $\mathrm{Fe}$ and $\mathrm{Mn}$ in soil.

Fig. 2(c) shows, unlike oxalic acid, the increasing humic acid added, in general, decreases Fe/Mn-F. With strong capacity of chelation and adsorption, humic acid, bearing negative charge, can absorb the cations in soil and form stable complex, inducing the dissociation of fluoride bound with $\mathrm{Fe}$ or $\mathrm{Mn}$ and its transformation into other forms, as the acid concentration increases. Therefore, Fe/Mn-F decreases with the increase amount of humic acid.

Thus, the effect of oxalic acid and humic acid on the transformation of $\mathrm{Fe} / \mathrm{Mn}-\mathrm{F}$ are different, the former one at a high concentration, decreases the activity of fluoride, but not activates the available fluoride; while the latter one promotes the transformation of $\mathrm{F}^{-}$in $\mathrm{Fe} / \mathrm{Mn}-\mathrm{F}$, mainly, to Or-F.

Effect of the amount of oxalic acid and humic acid added on the content of residual fluoride (Res-F): Most of the residual fluoride exists stably in soil as insoluble compound. Fig. 2(d) and Fig. 3(d) show that, the residual fluoride decreases rapidly as the concentration of oxalic acid is over $0.016 \mu \mathrm{g} / \mathrm{g}$. Whereas, the influence of humic acid is relatively weak, but still induce a slight decrease. The results indicate both of the oxalic acid and humic acid can activate the fluoride in soil. Oxalic acid can promote the transformation of residual fluoride to various other forms, mainly to available fluoride, while humic acid to exchangeable fluoride, but the decrease of fluoride of other species induce the decrease of residual fluoride to be a slight one. Thus, oxalic acid can activate the fluoride in soil more than humic acid.

The slight decrease of the residual fluoride with a large base would increase the fluoride of other species. The increase of water soluble fluoride and exchangeable fluoride will induce the enhancement of bioactivity, which to the farmland soil of high fluoride concentration, will increase the fluoride adsorption and in a long run, leading to negative effects.

Distribution of various species of fluoride after the adding of oxalic acid and humic acid: Table-5 indicates, after the addition of low-molecular-weight organic acid(oxalic acid) and high-molecular-weight organic acid (humic acid), the content of fluoride of various forms in soil follows the order: residual $\mathrm{F} \geq$ exchangeable $\mathrm{F} \geq$ water soluble $\mathrm{F} \geq \mathrm{Fe} /$ $\mathrm{Mn}-\mathrm{F} \geq \mathrm{Or}-\mathrm{F}$.

\begin{tabular}{|c|c|c|c|c|}
\hline \multicolumn{5}{|c|}{$\begin{array}{c}\text { TABLE-5 } \\
\text { AVERAGE PERCENTAGE OF VARIOUS SPECIES OF } \\
\text { FLUORIDE IN SOIL }(\%)^{*}\end{array}$} \\
\hline Species of fluoride & Ws-F & Ex-F & $\mathrm{Fe} / \mathrm{Mn}-\mathrm{F}$ & Res-F \\
\hline Original fluvo-aqui soil & 1.036 & 1.955 & 0.277 & 96.731 \\
\hline Oxalic acid fluvo-aqui soil & 2.891 & 4.293 & 1.292 & 91.525 \\
\hline Humic acid fluvo-aqui soil & 0.539 & 3.075 & 0.202 & 96.184 \\
\hline Original paddy soil & 0.161 & 0.769 & 0.105 & 98.966 \\
\hline Oxalic acid paddy soil & 1.224 & 2.178 & 0.802 & 95.796 \\
\hline Humic acid paddy soil & 0.09 & 1.179 & 0.057 & 98.674 \\
\hline \multicolumn{5}{|c|}{$\begin{array}{l}\text { *Notice: These were the average percentage of various species of } \\
\text { fluoride in the total content of fluoride after adding different amount of } \\
\text { oxalic acid or humic acid in soil, the percentage of Or-F is not discu- } \\
\text { ssed as its content is lower than the blank solution }\end{array}$} \\
\hline
\end{tabular}

Taking a comparison of the statistics in the Table-5, it can be referred that oxalic acid can increase and humic acid decrease the content of water soluble fluoride, while both of them increase that of exchangeable fluoride; oxalic acid can increase and humic acid decrease the content of Fe/Mn-F, while both of them decrease that of residual fluoride. And a significant decrease of residual fluoride can be observed after the concentration of oxalic acid is higher than $0.02 \mathrm{mmol} / \mathrm{g}$ as a result of residual fluoride being activated into other forms.

\section{Conclusion}

The content of fluoride of various species in the two soils follows the order: residual fluoride $\geq$ exchangeable fluoride $\geq$ water soluble fluoride $\geq \mathrm{Fe} / \mathrm{Mn}-\mathrm{F} \geq \mathrm{Or}-\mathrm{F}$; The soil $\mathrm{pH}$ value decreases rapidly with the oxalic acid concentration over 0.02 $\mathrm{mmol} / \mathrm{g}$; whereas the effect of humic acid on the soil $\mathrm{pH}$ value of different soils differs slightly, but induces all the $\mathrm{pH}$ values to approach to 6.0. Available fluoride (water soluble fluoride and exchangeable fluoride) and Fe/Mn-F increase and residual fluoride decrease with the increase of oxalic acid. Therefore, oxalic acid can, to some extent, activate fluoride in soil and has negative effect on crops. With the increase of humic acid, soluble fluoride $\mathrm{Fe} / \mathrm{Mn}-\mathrm{F}$ decreases, exchangeable fluoride increases and residual fluoride decreases slightly. Thus, closely related its chelate capacity, the activation effect of humic acid on fluoride is moderate.

When its content over $0.016 \mathrm{mmol} / \mathrm{g}$, oxalic acid has great influence on fluoride of various forms: bioavailable fluoride (water soluble fluoride and exchangeable fluoride) increases; while unbioavailable fluoride decreases, indicating oxalic acid 
promotes the dissolution of bioavailable fluoride and compared with humic acid, the capacity of oxalic acid to activate fluoride in soil is stronger. Therefore, the conclusion of this paper is, the capacity of low-molecular-weight organic acid to activate the fluoride in soil is stronger than that of high-molecularweight organic acid, thus the former one can induce a higher intake of fluoride by crops.

\section{ACKNOWLEDGEMENTS}

This research was financially supported the special fund of Argo-Geologic and Ecological Environment Survey of Zhu jiang delta economic region in Guangdong Province (No. 1212010511216) and Postdoctoral Research Foundation of University of Electronic Science and Technology of China.

\section{REFERENCES}

1. Cao Jin, Bai Xue-xin, Zhao Yan, et al., J. Environ. Heath Perspect., 104, 1340 (1996).

2. Chen Hui-Man, Environmental Soil Science, Science Press, Beijing (2005).

3. D. Santhi, V.U. Bhagan and R.L. Sarma, Asian J. Chem., 14, 177 (2002)

4. K.W. Perrot, B.F.L. Smith, R.H.E. Inkson, Eur. J. Soil Sci., 23, 58 (1976).

5. D.L. Jones, Plant and Soil, 205, 25. (1998).

6. B.W. Strobel, Geoderma, 99, 169 (2001).
7. M.-L. Song and Y.-L. Liu, Researches on the Land Degradation and its Control in China: Acidification of Tea Garden and its Control, Science Press, Beijing, pp. 370-379 (1990).

8. Q.R. Shen, An Introduction to Soil Fertilizer Science, Higher Education Press, Beijing, p. 272 (2001).

9. R.K. Xu, A.-Z. Zhao and G.-L. Ji, J. Colloid. Interf. Sci., 264, 322 (2003).

10. S.J. Cronin, V. Manoharan, M.J. Hedley and P. Loganathan, New Zealand J. Agric. Res., 43, 295 (2000).

11. X. Wang, Q. Li, J. Ding, M. Luo, T. Zhang and Y. Zhou, Anal. Sci., 23, 539 (2007).

12. H.-X. Lu and M. Geng, J. Anhui Inst. Edu., 23, 98 (2005).

13. R.-K. Xu and Y.-Y. Wang, Acta Scient. Circumstant., 23, 405 (2003).

14. R. Xu, Y. Wang, A. Zhao, G. Ji and H. Zhang, Environ. Geochem. Health, 28, 141 (2006)

15. C.L. Liu, C.L. Lin and Z.-L. Xie, J. Henan Normal Univ., (Nat. Sci.), 37, 84 (2009).

16. Agency of Urban and Rural Construction and Environmental Protection, Analysis Method of Environmental Monitoring, China Environmental Science Press, Beijing, pp. 316-318 (1983).

17. W.H. Wu, Z.M. Xie, J.M. Xu, Z.P. Hong and C. Liu, Environ. Sci., 23, 104 ( 2002) (In Chinese).

18. Chen Wen, Li Dong-Sheng, Fan Chang-Li, et al., Chin. J. Anal. Lab., 5, 11 (2009).

19. Z.-A. Li, B. Zou, H.-P. Xia, Y.-Z. Ding, W.-N. Tan and S.-L. Fu, Pedosphere, 18, 137 (2008)

20. A. Romar, C. Gago, M.L. Fernández-Marcos and E. Álvarez, Pedosphere, 19, 60 (2009)

21. Z.-M. Xie, W.H. Wu and J.-M. Xu, Adv. Environ. Sci., 7, 40 (1999).

22. Z.C. Shao and J.F. Chen, Acta Pedolog. Sinica, 21, 153 (1984). 